Original research

\title{
Detection of carbapenem resistance and virulence genes among Acinetobacter baumannii isolated from hospital environments in center of Iran
}

\author{
Mohsen Nazari ${ }^{1}$, Zohreh Youzbashi², Mansoor Khaledi33, Javad Fathi4, Hamed Afkhami3 ${ }^{\text {, }}$ \\ 1Department of Bacteriology, Pasteur Institute of Iran, Tehran, Iran \\ 2Department of Biology, Damghan Branch, Islamic Azad University, Damghan, Iran \\ 3Department of Medical Microbiology, Faculty of Medicine, Shahed University of Medical Science, Tehran, Iran \\ 4Department of Bacteriology and Virology, School of Medicine, Shiraz University of Medical Sciences, Shiraz, Iran
}

\begin{abstract}
Carbapenem-resistant Acinetobacter baumannii are the top urgent antibiotic resistance threat in the world. The aims of this study were the determination of carbapenem-resistant genes and virulence genes among isolates from hospital environments. In this study, A. baumannii isolated from hospital environments and evaluated its antibiotic resistance, virulence factors, and resistance genes. Of 258 samples, 58 showed growth of the target organism. Antibiotic susceptibility test results considered all the $A$. baumannii to be multidrug-resistant isolates with the highest resistance being $36.2 \%$ to ciprofloxacin; while the most effective antibiotics with $98.3 \%$ susceptibility was piperacillintazobactam. Of these 58 hospital environment isolates, 18 isolates were positive for Metallo betalactamase. Overall, 65\% of the isolates from hospital environments had many virulence factors. PCR assays demonstrated the highest and lowest positive results in $\operatorname{csg} A$ and $c v a C$ gene among hospital environment isolates. Results indicate that the determination of carbapenem-resistant genes and virulence genes among isolates from hospital environments is very important.
\end{abstract}

Keywords: Carbapenem resistance, Virulence gene, Non-clinical isolates, Acinetobacter baumannii

\section{Introduction}

Multidrug-resistant Acinetobacter baumannii is an opportunistic pathogen that causes nosocomial infections [1-3]. Infections caused by this bacterium have a high prevalence in hospitalized and immunocompromised patients who are admitted to intensive care units [4, 5]. These infections are ventilator-associated pneumonia, soft-tissue, urinary tract, and meningitis infections [6-8]. A. baumannii has an ability to survive for long periods the surfaces, sometimes even for several years [9]. Due to resistance to a broad range of antimicrobial agents can long-term

\footnotetext{
${ }^{*}$ Corresponding author:

Hamed Afkhami, Ph.D

Department of Medical Microbiology, Faculty of Medicine, Shahed University of Medical Science, Tehran, Iran

Tel/Fax: +989196652678

Email: hamedafkhami70@gmail.com

http://orcid.org/o00o-0002-1110-6447
}

Received: October, 27, 2020

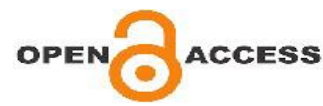

persistence in the clinical settings, surviving on nutrient sources and transmission by healthcare staff $[10,11]$.

Carbapenems and colistin are the last choices of antibiotic therapies against multi-drug resistant (MDR) A. baumannii strains [12]. The first carbapenem-resistant $A$. baumannii (CRAB) originated in the USA and was reported in 1991 [13]. Recent studies have reported that $\mathrm{CRAB}$ is a major causative organism in hospital-acquired infections [14]. Several mechanisms are responsible for resistance to carbapenems in $\mathrm{CRAB}$ [15]. The 
production of carbapenemase enzymes is one of the important mechanisms of carbapenem resistance. These enzymes are class A, B, and D according to molecular Ambler classification. The members of class A carbapenemases include SME, IMI, NMC, GES, SFC, and KPC families. Also, class B enzymes are called metallo-beta-lactamases (MBLs), including IMP, VIM, SIM, and NDM. Class D $\beta$-lactamases referred to OXA-type enzymes or oxacillinases which are the most prevalent carbapenemases in $A$. baumannii $[16,17]$. Prevalence of virulence Factors (VF) is contributed to pathogenesis in A. baumannii [18]. Some of the most significant VF of the $A$. baumannii strains are curli fibers (csg), colicin V production (cvaC), siderophores like aerobactin (iutA), and cytotoxic necrotizing factor (cnf) [18, 19]. The characterization of latent virulence genes, antimicrobial resistance, and molecular detection of carbapenemases of this bacterium in the hospital environments on abiotic and biotic surfaces are the important epidemiological issue. The aims of this study were the determination of antimicrobial resistance and molecular detection of antibiotic resistance and virulence genes among $A$. baumannï isolated from hospital environments in Qom hospitals.

\section{Materials and Methods}

2.1 Bacterial strain collection and identification

The study was conducted at Pasteur Institute in the period from October 2019 to December 2019. Totally, 58 isolates were collected from different hospital environments of Qom hospitals (Kamkar and Beheshti hospitals) (Table 1). Samples were washed with PBS and transferred to brain heart infusion (BHI) media for further incubation at $37^{\circ} \mathrm{C}$. Samples were inoculated into blood agar and MacConkey agar for standard aerobic growth and placed at $37{ }^{\circ} \mathrm{C}$ overnight. The isolates were identified by the standard biochemical tests. The final confirmation of $A$. baumannii isolates was performed by PCR blaoXA-51like gene [20].

\subsection{Antimicrobial susceptibility testing}

According to the CLSI 2019 guidelines, the disk diffusion test was performed on Mueller-Hinton agar using a panel of nine antibiotic disks including ciprofloxacin (CIP), levofloxacin (LVX), gentamicin (GM), imipenem (IMI), piperacillin-tazobactam (PTZ), ampicillin-sulbactam (SAM), ceftriaxone
(CRO), and trimethoprim-sulfamethoxazole (SXT) (Mast Diagnostic, UK).

\subsection{Phenotypic detection of MBL production}

Combined disk diffusion test (CDDT) was performed using an imipenem disk (Mast Diagnostic, UK) and in combination with EDTA (Sigma, UK) to identify MBLs. The inhibition zones of the imipenem, and imipenem + EDTA disks were compared after 20 $\mathrm{h}$ of incubation at $37^{\circ} \mathrm{C}$. In the combined disc test, if the increase in inhibition zone with the imipenem + EDTA disk was $>7 \mathrm{~mm}$ than the imipenem disk alone, it was considered as MBL positive [21].

\subsection{Detection of carbapenem resistance and virulence genes \\ Genomic DNA extractions were performed based on the protocol as described elsewhere [22]. PCR reaction mixtures were prepared in total volumes of 25 $\mu \mathrm{l}$. The presence of the carbapenemase-encoding genes including bla ${ }_{\mathrm{OXA2} 2}-$ like, blaOXA24-like, blaOXA58- like, bla $a_{\mathrm{IMP}}$, bla $a_{\mathrm{NDM}}$, and blavim genes and virulence genes $\operatorname{cnfi}, \operatorname{csg} A, \operatorname{cvaC}$, iut $A$ were investigated by PCR assays in all isolates [23-28]. All PCR primers are shown in Table 2.}

Table 1. Samples source collection

\begin{tabular}{lc}
\hline Source & $\begin{array}{c}\text { Amount } \\
\text { Percent (Number/Total) }\end{array}$ \\
\hline Sink & $5.1 \%(3 / 58)$ \\
\hline Floor & $6.8 \%(4 / 58)$ \\
\hline Pillow & $12.0 \%(7 / 58)$ \\
\hline Desk & $13.7 \%(8 / 58)$ \\
\hline Bed & $3.4 \%(2 / 58)$ \\
\hline Under-bed wheels & $8.6 \%(5 / 58)$ \\
\hline Door knob & $12.0 \%(7 / 58)$ \\
\hline Nurses' fingers & $5.1 \%(3 / 58)$ \\
\hline Walls & $10.2 \%(6 / 58)$ \\
\hline Touchpads & $22.4 \%(13 / 58)$ \\
\hline
\end{tabular}




\section{Results}

Antibiotic susceptibility testing showed out of 58 hospital environment isolated strains, the resistance against to CIP, LVX, GM, IMI, SXT, SAM, CRO, and PTZ were 36.2\% (21/58), 31\% (18/58), 18.9\% (11/58), $15.5 \%$ (9/58), 8.6\% (5/58), 8.6\% (5/58), 5.1\% (3/58) and $1.7 \%(1 / 45)$, respectively.

Of these 58 hospital environment isolates, 21/58 (36.2\%) showed resistance to imipenem and were therefore further tested for MBL production. Eighteen of these isolates showed positive results for MBL production by CDDT method as shown in Table 3 .

PCR analysis in all carbapenem-resistant isolates revealed that prevalence of blaviM, bla ${ }_{\mathrm{OXA}-23}$-like, blaoxA-24-like, and bla IMP were 10/21 (47.6\%), 3/21 (14.3\%), 3/21 (14.3\%), and 1/21 (4.7\%) of the strains, respectively. None of the hospital environment isolates carried blaoXA-58-like or bla NDM (Table 3).

Also, PCR assays demonstrated positive results in 43.1\% (25/58) of strains for $\operatorname{csg} A, 32.7 \%(19 / 58)$ of strains for cnfi, $12 \%(7 / 58)$ of strains for iutA, and $3.4 \%$ (2/58) of strains for $c v a C$ genes among hospital environment isolates (Table 3 ).

\section{Discussion}

A. baumannii is an opportunistic pathogen and also has the ability to cause nosocomial diseases due to antibiotic resistance and can survive on surfaces, the body of the treatment staff, and patients [29, 30]. This bacterium has the ability to survive on different surfaces and objects, so it has a high potential for spread and colonization in hospitalized patients [31]. Through the mechanisms of acquisition of determinants of resistance and upregulation of intrinsic resistance mechanisms, this bacterium is able to resistance against a wide range of available antibiotics [30]. A. baumannii with multidrug resistance causes severe infections and high mortality, especially in patients with impaired immune systems or immunocompromised [2, 32]. Although the virulence factors and pathogenicity mechanism of $A$. baumannii are not fully understood and require further study and research, but this bacterium has the ability to cause a wide range of infections and deaths in hospitals. The virulence factors of this bacterium play an important role in resisting the host's defense mechanism [33, 34]. Also these factors are important

Table 2. Primers used for amplification

\begin{tabular}{|c|c|c|c|}
\hline Target gene & Primers sequence (5' to $\left.3^{\prime}\right)$ & Size (bp) & Reference \\
\hline$b l a_{\mathrm{NDM}}$ & $\begin{array}{l}\text { F: CGGAATGGCTCATCACGATC } \\
\text { R: CGGAATGGCTCATCACGATC }\end{array}$ & 621 & [23] \\
\hline$b l a_{\mathrm{IMP}}$ & $\begin{array}{l}\text { F: GTTTATGTTCATACWTCG } \\
\text { R: GGTTTAAYAAAACAACCAC }\end{array}$ & 432 & [24] \\
\hline$b l a_{\mathrm{VIM}}$ & $\begin{array}{l}\text { F: TTTGGTCGCATATCGCAACG } \\
\text { R: CCATTCAGCCAGATCGGCAT }\end{array}$ & 500 & [25] \\
\hline bla $a_{\text {OXA-23-like }}$ & $\begin{array}{l}\text { F: TCTGGTTGTACGGTTCAGC } \\
\text { R: AGTCTTTCCAAAAATTTTG }\end{array}$ & 606 & [26] \\
\hline$b l a_{\text {OXA-24-like }}$ & $\begin{array}{l}\text { F: ATGAAAAAATTTATACTTCC } \\
\text { R: TTAAATGATTCCAAGATTTTC }\end{array}$ & 246 & [26] \\
\hline bla ${ }_{\text {OXA-58-like }}$ & $\begin{array}{l}\text { F: ATGAAATTATTAAAAATATTGAGTTTAG } \\
\text { R: TTATAAATAATGAAAAACACCCAAC }\end{array}$ & 843 & [26] \\
\hline bla $a_{\text {OXA-51-like }}$ & $\begin{array}{l}\text { F: TAATGCTTTGATCGGCCTTG } \\
\text { R: TGGATTGCACTTCATCTTGG }\end{array}$ & 353 & [27] \\
\hline cnfl & $\begin{array}{l}\text { F: AAGATGGAGTTTCCTATGCAGGAG } \\
\text { R: CATTCAGAGTCCTGCCCTCATTATT }\end{array}$ & 498 & [28] \\
\hline $\operatorname{csg} A$ & $\begin{array}{l}\text { F: ACTCTGACTTGACTATTACC } \\
\text { R: AGATGCAGTCTGGTCAAC }\end{array}$ & 200 & {$[28]$} \\
\hline$c v a C$ & $\begin{array}{l}\text { F: CACACACAAACGGGAGCTGTT } \\
\text { R: CTTCCCGCAGCATAGTTCCAT }\end{array}$ & 680 & [28] \\
\hline iutA & $\begin{array}{l}\text { F: GGCTGGACATCATGGGAACTGG } \\
\text { R: CGTCGGGAACGGGTAGAATCG }\end{array}$ & 300 & [28] \\
\hline
\end{tabular}

F: Forward; R: Reverse 
Table 3. Positive and negative genes among hospital environment isolates

\begin{tabular}{|c|c|c|c|c|c|c|c|c|c|c|c|}
\hline $\begin{array}{l}\text { Sample } \\
\text { No. }\end{array}$ & MBL & $b^{\prime} a_{\mathrm{VIM}}$ & bla OXA-23-like & bla OXA-24-like & $b l a_{\mathrm{IMP}}$ & bla $0 \times$ A-58-like & $b l a_{\mathrm{NDM}}$ & $c \operatorname{cg} A$ & cnf1 & iutA & cvaC \\
\hline 1 & - & - & - & - & - & - & - & - & + & - & - \\
\hline 2 & - & - & - & - & - & - & - & + & - & - & - \\
\hline 3 & - & - & - & - & - & - & - & + & + & - & - \\
\hline 4 & + & + & - & - & - & - & - & - & + & - & - \\
\hline 5 & - & - & - & - & - & - & - & + & - & - & - \\
\hline 6 & + & - & + & - & - & - & - & + & - & - & - \\
\hline 7 & + & - & - & - & - & - & - & + & + & - & - \\
\hline 8 & + & + & - & - & - & - & - & + & - & - & - \\
\hline 9 & - & - & - & - & - & - & - & + & + & - & + \\
\hline 10 & + & + & - & - & - & - & - & + & - & - & - \\
\hline 11 & - & - & - & - & - & - & - & - & + & - & - \\
\hline 12 & + & - & - & + & - & - & - & + & - & - & - \\
\hline 13 & - & - & - & - & - & - & - & + & - & - & - \\
\hline 14 & + & + & + & - & + & - & - & + & + & - & - \\
\hline 15 & - & - & - & - & - & - & - & + & - & - & - \\
\hline 16 & - & - & - & - & - & - & - & + & - & - & - \\
\hline 17 & + & - & - & - & - & - & - & - & + & + & - \\
\hline 18 & - & - & - & - & - & - & - & - & - & + & - \\
\hline 19 & + & + & - & + & - & - & - & + & + & - & - \\
\hline 20 & - & - & - & - & - & - & - & - & - & + & - \\
\hline 21 & - & - & - & - & - & - & - & - & - & + & - \\
\hline 22 & + & - & - & - & - & - & - & + & - & - & - \\
\hline 23 & - & - & - & - & - & - & - & + & + & - & - \\
\hline 24 & + & - & - & - & - & - & - & + & - & - & - \\
\hline 25 & + & + & - & - & - & - & - & - & + & + & - \\
\hline 26 & + & - & - & - & - & - & - & + & + & - & - \\
\hline 27 & - & - & - & - & - & - & - & + & - & - & - \\
\hline 28 & - & - & - & - & - & - & - & + & + & - & - \\
\hline 29 & - & - & - & - & - & - & - & - & + & - & - \\
\hline 30 & + & + & + & - & - & - & - & + & + & - & - \\
\hline 31 & + & + & - & - & - & - & - & + & - & - & - \\
\hline 32 & + & + & - & - & - & - & - & + & - & - & - \\
\hline 33 & - & - & - & - & - & - & - & - & + & - & - \\
\hline 34 & + & - & - & - & - & - & - & + & + & - & - \\
\hline 35 & - & - & - & - & - & - & - & - & - & + & - \\
\hline 36 & + & + & - & + & - & - & - & + & + & - & - \\
\hline 37 & - & - & - & - & - & - & - & - & - & + & - \\
\hline 38 & - & - & - & - & - & - & - & - & + & - & - \\
\hline $39-58$ & - & - & - & - & - & - & - & - & - & - & - \\
\hline
\end{tabular}

role in binding and invasion bacteria to host cells [28]. According to the contents, it is necessary to study the prevalence of antibiotic resistance and prepare a useful antibiotic treatment model to control and treat diseases caused by A. baumanniï. The most important factor in resistance to carbapenem antibiotics is the presence of the blaoxa genes, which causes the production of carbapenem hydrolyzing enzymes. In the present study, out of 58 isolates, the rate of antibiotic resistance in A. baumannii based on antibiotic susceptibility tests was the highest and lowest resistance for CIP and PTZ antibiotics, respectively. According to Nourbakhsh et al. (2018) studies, the highest resistance is related to CIP (97.2\%) [35], which is similar to our study in terms of the highest antibiotic resistance. In the study of Shakibaie et al., resistance to CIP and PTZ was reported to be $66 \%$ and $93.3 \%$, respectively [36]. Although the 
bacterial resistance to CIP was as high as in our study, the resistance to PTZ differed greatly from our study. According to a study by Shirmohammadlou et al., $A$. baumannii is completely resistant to CIP [37], and this result is consistent with our study. These results are consistent with the study of Kabbaj et al., which showed that MBL production is among the $74 \%$ of bacteria resistant to imipenem [38].

Among carbapenem-resistant isolates, the frequency of blavim and bla Imp genes had the highest and lowest, respectively. Also none of the hospital

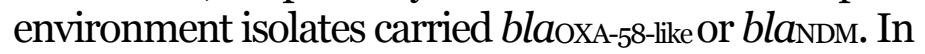
the study of Amudhan et al. [39], the most resistance is related to blavim in $45 \%$, and in the study of Shirmohammadlou et al. [37], resistance to bla IMP was less common, which met with our study.

Regard to prevalence of virulence genes, the results of our study were similar to those of Al-Kadmy et al. (Highest frequency was csgA 66.7\% and lowest frequency was cvaC 9.5\%) [40], Momtaz et al. (Highest frequency was $\operatorname{csg} A 55 \%$ and lowest frequency was $c v a C$ 10\%) [41], although our results contradicted the results of Darvishi study (highest frequency was $c n f 1,35.53 \%$ and lowest frequency was $\operatorname{csg} A$ 12.39\%) [28].

The present study had some limitations. Mainly, this was a two-center study; therefore, the generalization of the results to other regions requires further investigations.

In conclusion, increasing antibiotic resistance due to the acquisition of resistance genes and mutations due to selective pressures is a global problem. The increase in antibiotic resistance in A. baumannii is spreading, especially against effective antibiotics. Therefore, Studying and determining the pattern of antibiotic resistance for the preparation of a treatment protocol and the use of appropriate antibiotics is effective and reduces the increase in antibiotic resistance. In the current study, we isolated $A$. baumannii from hospital environments and determinated its antibiotic resistance, virulence factor, and resistance gene. Antibiotic susceptibility testing showed the most resistance and sensitivity was against CIP and PTZ respectively. PCR analysis in all carbapenem-resistant isolates revealed a high prevalence of blavim and bla IMP. Also, results demonstrated the highest and lowest positive results for $\operatorname{csg} A$ and $c v a C$ gene among hospital environment isolates.

\section{Acknowledgments}

We would like to thank the Pasteur Institute of Iran and Kamkar and Beheshti hospitals of Qom for supporting this study.

\section{Author Contributions}

MN, HA: conceived and design the study. JF, MN, MK: supervised data collectors. MK, JF, ZY and HA: drafting the article or revisiting it critically for important intellectual content. All authors read and approved the final manuscript.

\section{Conflict of Interest}

We declare that we have no conflict of interest.

\section{Ethical declarations}

This study was in accordance with the declaration of Helsinki and ethical permission was sought from the institutional Ethics Committee of Pasteur Institute of Iran, Tehran, Iran (Ethical Code: 1398057). However, because we only used leftovers from clinical specimens, the local ethics committee waived the need for informed consent.

\section{Financial Support}

This work was supported by Pasteur Institute of Iran, Tehran, Iran (grants No. 41443).

\section{References}

1. Hashemi B, Afkhami H, Khaledi M, Kiani M, Bialvaei AZ, Fathi $\mathrm{J}$, et al. Frequency of Metalo beta Lactamase genes, bla IMP1, INT 1 in Acinetobacter baumanii isolated from burn patients North of Iran. Gene Rep. 2020; 21:100800.

2. Howard A, O'Donoghue M, Feeney A, Sleator RD. Acinetobacter baumannii: an emerging opportunistic pathogen. Virulence. 2012; 3(3):243-50.

3. Khaledi M, Shahini Shams Abadi M, Validi M, Zamanzad B, Vafapour R, Gholipour A. Phenotypic and genotypic detection of metallo- $\beta$-lactamases in $\mathrm{A}$. baumanii isolates obtained from clinical samples in Shahrekord, southwest Iran. BMC Res Notes. 2019; $12(1): 597$.

4. Malekzadegan Y, Abdi A, Heidari H, Moradi M, Rastegar E, Sedigh Ebrahim-Saraie H. In vitro activities of colistin, imipenem and ceftazidime against drug-resistant Pseudomonas aeruginosa and Acinetobacter baumannii isolates in the south of Iran. BMC Res Notes. 2019; 12(1):301.

5. Patel SJ, Oliveira AP, Zhou JJ, Alba L, Furuya EY, Weisenberg SA, et al. Risk factors and outcomes of infections caused by extremely drug-resistant gram-negative bacilli in patients hospitalized in intensive care units. Am J Infect Control. 2014; 42(6):626-31.

6. Basatian-Tashkan B, Niakan M, Khaledi M, Afkhami H, Sameni F, Bakhti S, et al. Antibiotic resistance assessment of Acinetobacter 
baumannii isolates from Tehran hospitals due to the presence of efflux pumps encoding genes (adeA and adeS genes) by molecular method. BMC Res Notes. 2020; 13(1):543.

7. Khaledi M, Asadi-Samani M, Mahmoodi-Kouhi A, Gholipour A. Antibacterial effect of the hydroalcoholic extracts of four Iranian medicinal plants on Staphylococcus aureus and Acinetobacter baumanii. Int J Pharm Phytopharm Res. 2017; 7(2):10-4.

8. Rit K, Saha R. Multidrug-resistant acinetobacter infection and their susceptibility patterns in a tertiary care hospital. Niger Med J. 2012; 53(3):126-8.

9. Vijayakumar S, Rajenderan S, Laishram S, Anandan S, Balaji V, Biswas I. Biofilm Formation and Motility Depend on the Nature of the Acinetobacter baumannii Clinical Isolates. Front Public Health. 2016; 4:105.

10. Almasaudi SB. Acinetobacter spp. as nosocomial pathogens: Epidemiology and resistance features. Saudi J Biol Sci. 2018; 25(3):586-96.

11. Eveillard M, Kempf M, Belmonte O, Pailhoriès H, Joly-Guillou ML. Reservoirs of Acinetobacter baumannii outside the hospital and potential involvement in emerging human communityacquired infections. Int J Infect Dis. 2013; 17(10):e802-5.

12. Lee CR, Lee JH, Park M, Park KS, Bae IK, Kim YB, et al. Biology of Acinetobacter baumannii: Pathogenesis, Antibiotic Resistance Mechanisms, and Prospective Treatment Options. Front Cell Infect Microbiol. 2017; 7:55.

13. Go ES, Urban C, Burns J, Kreiswirth B, Eisner W, Mariano N, et al. Clinical and molecular epidemiology of acinetobacter infections sensitive only to polymyxin B and sulbactam. Lancet. 1994; 344(8933):1329-32.

14. Li J, Rayner CR, Nation RL, Owen RJ, Spelman D, Tan KE, et al. Heteroresistance to colistin in multidrug-resistant Acinetobacter baumannii. Antimicrob Agents Chemother. 2006; 50(9):2946-50.

15. Olaitan AO, Berrazeg M, Fagade OE, Adelowo OO, Alli JA, Rolain JM. Emergence of multidrug-resistant Acinetobacter baumannii producing OXA-23 carbapenemase, Nigeria. Int $\mathrm{J}$ Infect Dis. 2013; $17(6):$ e469-70.

16. Hsu LY, Apisarnthanarak A, Khan E, Suwantarat N, Ghafur A, Tambyah PA. Carbapenem-Resistant Acinetobacter baumannii and Enterobacteriaceae in South and Southeast Asia. Clin Microbiol Rev. 2017; 30(1):1-22.

17. Jeon JH, Lee JH, Lee JJ, Park KS, Karim AM, Lee CR, et al. Structural basis for carbapenem-hydrolyzing mechanisms of carbapenemases conferring antibiotic resistance. Int $J$ Mol Sci. 2015; 16(5):9654-92.

18. Eijkelkamp BA, Stroeher UH, Hassan KA, Paulsen IT, Brown MH. Comparative analysis of surface-exposed virulence factors of Acinetobacter baumannii. BMC Genomics. 2014; 15(1):1020.

19. Eraç B, Yılmaz FF, Hoşgör Limoncu M, Oztürk I, Aydemir S. [Investigation of the virulence factors of multidrug-resistant Acinetobacter baumannii isolates]. Mikrobiyol Bul. 2014; 48(1):70-81.

20. Safari M, Mozaffari Nejad AS, Bahador A, Jafari R, Alikhani MY. Prevalence of ESBL and MBL encoding genes in Acinetobacter baumannii strains isolated from patients of intensive care units (ICU). Saudi J Biol Sci. 2015; 22(4):424-9.

21. Fallah F, Hakemi Vala M, Goudarzi H, Hashemi A, Taherpour A, Bigdel Shamloo K. Identification of extended-spectrumbetalactamases (ESBLs), metallo-betalactamases (MBLs), Amp-C and
KPC Blactamases among Klebsiella pneumoniae isolated from adults and pediatric patients in Iran. Afr J Microbiol Res. 2013; 7 (25):3254-61.

22. Gräser Y, Klare I, Halle E, Gantenberg R, Buchholz P, Jacobi $\mathrm{HD}$, et al. Epidemiological study of an Acinetobacter baumannii outbreak by using polymerase chain reaction fingerprinting. J Clin Microbiol. 1993; 31(9):2417-20.

23. El-Shazly S, Dashti A, Vali L, Bolaris M, Ibrahim AS. Molecular epidemiology and characterization of multiple drug-resistant (MDR) clinical isolates of Acinetobacter baumannii. Int $J$ Infect Dis. 2015; 41:42-9.

24. Higgins PG, Lehmann M, Wisplinghoff H, Seifert H. gyrB multiplex PCR to differentiate between Acinetobacter calcoaceticus and Acinetobacter genomic species 3. J Clin Microbiol. 2010; 48(12):4592-4.

25. Hujer KM, Hujer AM, Hulten EA, Bajaksouzian S, Adams JM, Donskey CJ, et al. Analysis of antibiotic resistance genes in multidrug-resistant Acinetobacter sp. isolates from military and civilian patients treated at the Walter Reed Army Medical Center. Antimicrob Agents Chemother. 2006; 50(12):4114-23.

26. Srinivasan VB, Rajamohan G, Pancholi P, Stevenson K, Tadesse D, Patchanee P, et al. Genetic relatedness and molecular characterization of multidrug resistant Acinetobacter baumannii isolated in central Ohio, USA. Ann Clin Microbiol Antimicrob. 2009; 8:21.

27. Turton JF, Woodford N, Glover J, Yarde S, Kaufmann ME, Pitt TL. Identification of Acinetobacter baumannii by detection of the blaOXA-51-like carbapenemase gene intrinsic to this species. J Clin Microbiol. 2006; 44(8):2974-6.

28. Darvishi M. Virulence factors profile and antimicrobial resistance of Acinetobacter baumannii strains isolated from various infections recovered from immunosuppressive patients. Biomed Pharmacol J. 2016; 9(3):1057-62.

29. Jahangiri S, Malekzadegan Y, Motamedifar M, Hadi N. Virulence genes profile and biofilm formation ability of Acinetobacter baumannii strains isolated from inpatients of a tertiary care hospital in southwest of Iran. Gene Rep. 2019; 17:100481.

30. Nowak P, Paluchowska PM, Budak A. Co-occurrence of carbapenem and aminoglycoside resistance genes among multidrug-resistant clinical isolates of Acinetobacter baumannii from Cracow, Poland. Med Sci Monit Basic Res. 2014; 20:9-14.

31. Choi WS, Kim SH, Jeon EG, Son MH, Yoon YK, Kim JY, et al. Nosocomial outbreak of carbapenem-resistant Acinetobacter baumannii in intensive care units and successful outbreak control program. J Korean Med Sci. 2010; 25(7):999-1004.

32. Poirel L, Bonnin RA, Nordmann P. Genetic basis of antibiotic resistance in pathogenic Acinetobacter species. IUBMB Life. 2011; 63(12):1061-7.

33. Antunes LC, Imperi F, Carattoli A, Visca P. Deciphering the multifactorial nature of Acinetobacter baumannii pathogenicity. PLoS One. 2011; 6(8):e22674.

34. López-Rojas R, Domínguez-Herrera J, McConnell MJ, Docobo-Peréz F, Smani Y, Fernández-Reyes M, et al. Impaired virulence and in vivo fitness of colistin-resistant Acinetobacter baumannii. J Infect Dis. 2011; 203(4):545-8.

35. Nourbakhsh F, Tajbakhsh E, Daneshmand D, Borooni S, Nourbakhsh V. Antibiotic Resistance Patterns and Molecular 


\section{Nazari et al.}

Typing of Acinetobacter Baumannii Strains Isolated from Burn Patients in Iran. Int J Med Lab. 2018; 5(4):278-87.

36. Shakibaie MR, Adeli S, Salehi MH. Antibiotic resistance patterns and extended-spectrum $\beta$-lactamase production among Acinetobacter spp. isolated from an intensive care Unit of a hospital in Kerman, Iran. Antimicrob Resist Infect Control. 2012; 1(1):1.

37. Shirmohammadlou N, Zeighami H, Haghi F, Kashefieh M. Resistance pattern and distribution of carbapenemase and antiseptic resistance genes among multidrug-resistant Acinetobacter baumannii isolated from intensive care unit patients. J Med Microbiol. 2018; 67(10):1467-73.

38. Kabbaj H, Seffar M, Belefquih B, Akka D, Handor N, Amor M, et al. Prevalence of Metallo- $\beta$-Lactamases Producing
Acinetobacter baumannii in a Moroccan Hospital. ISRN Infect Dis. 2013; 2013:154921.

39. Amudhan MS, Sekar U, Kamalanathan A, Balaraman S. bla(IMP) and bla(VIM) mediated carbapenem resistance in Pseudomonas and Acinetobacter species in India. J Infect Dev Ctries. 2012; 6(11):757-62.

40. Al-Kadmy IMS, Ali ANM, Salman IMA, Khazaal SS. Molecular characterization of Acinetobacter baumannii isolated from Iraqi hospital environment. New Microbes New Infect. 2018; 21:51-7. 41. Momtaz H, Seifati SM, Tavakol M. Determining the Prevalence and Detection of the Most Prevalent Virulence Genes in Acinetobacter Baumannii Isolated From Hospital Infections. Int $J$ Med Lab. 2015; 2(2):87-97. 